\title{
The use and limitations of isotope studies in clinical shock
}

\author{
M. D. A. VICKERS* \\ Dudley Road Hospital, Birmingham
}

\begin{abstract}
Summary
Blood volume measurements can only be of value in the treatment of clinical shock if the results are obtained quickly. In a changing situation, such as continuing haemorrhage, erroneous conclusions are inevitable.

Assumptions which are commonly made concerning tracer loss rates and mixing rates may be invalid. Semi-automated machines can introduce new sources of error.

The measurement of blood volume should be regarded as an aid to assessing the relative contributions of intravascular volume and vascular tone to the resulting intravascular pressures.
\end{abstract}

\section{Problems with single tracers}

The principle use of isotopes in clinical shock has been in the determination of blood volume. Only a simultaneous measurement of both red cell mass and plasma volume can give a direct measurement of the blood volume; a single tracer technique always involves assumptions which may not be valid in the particular circumstances. This is because isotope techniques initially measure a tracer-dilution volume.

If the venous blood were representative of the whole circulation, this would be the same as the blood volume, and by measuring the haematocrit, red cell mass and plasma volume could be calculated equally well from either a red cell or plasma tracerdilution volume.

However, if one measures both these dilution volumes simultaneously, the plasma tracer-dilution volume is found to be considerably greater than the red cell tracer-dilution volume. Using the haematocrit of the sample, the red cell and plasma volumes can be calculated and the sum of these gives the total blood volume. Under most circumstances a plasma tracer-dilution volume is larger than the blood volume and a red cell tracer-dilution volume is smaller. The size of the discrepancy increases with the haematocrit, and at a haematocrit of $60 \%$ the plasma tracer-dilution volume exceeds the actual blood volume by $15 \%$. Although they are called blood volume computers, semi-automated machines, 18.

*Present address: Dudley Road Hospital, Birmingham since they use a single tracer, give an answer which is, in fact a dilution volume.

The discrepancy between a tracer-dilution volume and the blood volume exists because the haematocrit of blood drawn from large vessels differs from the haematocrit of the body as a whole, when this is calculated from red cell and plasma volumes measured independently. The ratio between the whole body haematocrit and the venous haematocrit has been called the F cell ratio (Reeve et al., 1953). The ratio is about 0.9 in normal circulatory states. It is possible to convert a single tracer-dilution volume into the blood volume by assuming a normal value for this ratio, measuring the actual venous haematocrit, and applying a correction factor. These factors have been published (Heath \& Vickers, 1968).

It is important to bear this discrepancy in mind when comparing measurements with predictions of blood volume. This, of course, is particularly relevant in clinical shock. A patient's normal blood volume is rarely known when he presents in a state of shock, and the value of a measurement will depend on how well it can be correlated with expectation. The best correlation between blood volume and simple body parameters has been made when using sex, weight and a cubed-height formula (Nadler, Hidalgo \& Bloch, 1962). It is important to realize that the equations were either derived from simultaneous measurements of both volumes or from a dilution volume corrected by assuming a normal $F$ cell ratio. The published nomograms are blood volume predictions, therefore, and not dilution volume predictions, and single tracer volumes should be corrected before being compared with such predictions of normal.

However, to make this correction one must assume a value for the $F$ cell ratio, and it is clearly important to know how far this is justified in states of shock.

The $F$ cell ratio is the resultant of the haematocrit of various parts of the circulation. The spleen has a pool of red cells, and this by itself would produce a higher whole-body haematocrit than the venous value, and patients with splenomegaly have a high F cell ratio (Brozovic et al., 1966). This is counterbalanced by a relative excess of plasma in the liver, 
kidney and capillaries (Allen \& Reeve, 1953; Pappenheimer \& Kintner, 1956). Thus the ratio remains reasonably constant when the distribution of blood flow is normal (Chaplin, Mollison \& Vetter, 1953).

However, it has generally been found to be more variable in states of shock, or associated with surgery or anaesthesia (Hope \& Verel, 1955; Remington \& Baker, 1961; Smith \& Moore, 1962; Grable et al., 1962; Karlson \& Senn, 1963). It should be borne in mind, of course, that failure to find consistency may be poor methodology, and not all workers have published the reproducibility of their techniques. Assuming a value of 0.9 for the F cell fraction when in fact it was 1.0 would, of course, re-introduce errors comparable with those discussed earlier.

\section{Choice of tracer}

One must, nevertheless, accept the potential errors of single tracer studies in the management of clinical shock. Double tracer techniques demand either sophisticated apparatus or careful laboratory manipulation, and are not suited to producing an answer quickly. In the choice of tracer there are factors in favour of both cell and plasma labels. Red cells have a slightly faster mixing rate, which may be particularly valuable in shock, and there is no loss of tracer from the circulation. On the other hand, only exceptionally heavy routine use could justify maintaining a stock of ready-labelled Onegative donor cells, and the alternative of labelling the patient's own cells requires some laboratory facilities and imposes an additional minimum delay of $40 \mathrm{~min}$ between deciding on the need for the estimation and getting an answer. The balance in favour of an albumin tracer has been tilted even further by the ready availability of ${ }^{125}$ I-labelled albumin, which has a useful shelf life, requires much less shielding, and gives a smaller radiation dose. Semi-automated machines using this isotope have brought blood volume measurements within the reach of all clinicians.

\section{Special problems with semi-automated machines}

Although the discrepancy between iodine-dilution volume and blood volume is one of the biggest sources of potential error with these machines, a few others are relevant to this symposium.

The measurement depends on counting radioactive disintegrations. These are random events, and the larger the number of counts recorded, the more accurately will any observed counting rate represent the mean counting rate. The confidence interval for any count is, therefore, dependent on the total number of counts. The semi-automated machines count 10,000 counts when the isotope is fresh and the $95 \%$ confidence interval for this number is $\pm \mathbf{2 \cdot 8} \%$ for a computation depending on two counts.
The machine will not automatically reject a dose as? too weak until it is registering only just over 4,00000 counts. The $95 \%$ confidence interval for two counts of this size is $\pm 4.3 \%$. The computation involves the difference between background and the dilution? sample counts. For the first estimation this is large but after a second dose of isotope, dilution sampleso are only a little more than double the activity of the background samples. Successive doses of isotope progressively reduce the difference, and the $95 \%$ confidence interval for the difference increases to unacceptable levels unless the difference between the background and the dilution samples counts is $\vec{\omega}$ at least half as high as the background counts alone. Incorrect placing of the dose cartridge, sedimenta-0 tion of the sample, incorrect filling of the sample syringes and mains voltage surges can all adde statistically highly significant errors (Heath \& Vickers, 1968), although many of them can be avoided by careful technique.

\section{Other technical problems}

Irrespective of the method of measurement thereare aspects of methodology that deserve specia consideration in the context of clinical shock.

Mixing of tracer must be complete before the dilus:s? tion samples are assayed. In shock, mixing has begn found to be delayed by Weil, Shubin \& Rosoff (1969) Noble \& Gregersen (1946) and Suzuki, Baker \& Sh\& maker (1964), but others have failed to confirm thiso (Hoye, Ketcham \& Berlin, 1966; Birkeland, 1966). However, the delay which has been found has nop been very great and a sample at 15 or 20 min wouldo be satisfactory. Apart from the special circumstances of burns and local trauma, loss rates are not $a b_{\overrightarrow{0}}^{\overrightarrow{0}}$ normal in shock. There are reasons for thinking that a single sample at about $15 \mathrm{~min}$ is as accurate as attempting to correct for loss rates by linear? logarithmic plotting of successive dilution volumeso and extrapolating to zero time (Heath, Vickers \& Dunlap, 1969).

In shock states it may be difficult to sample freely from veins, and to obtain separate veins for injectinge isotopes and taking samples. Stasis caused by tourniquets is theoretically capable of producing errors? with plasma labels by altering the haematocrit of thes sample. Several investigators, however, have been unable to detect errors when stasis has been deliberately produced (Underwood, Boyan \& Howland 1966; Heath et al., 1969). It is also possible to useo the same vein for injecting isotopes and takingw samples, if suitable precautions are taken (Fisk \& Bodlander, 1967; Heath et al., 1969).

The place of blood volume measurements in shock

Shock is a clinical diagnosis, and should be treatedए initially by transfusion. Treatment must not waif 
upon blood volume measurement. As soon as possible central venous pressure should be monitored and used as a guide to transfusion. In the majority of cases this will lead to a completely satisfactory restoration of normal cardiovascular dynamics. In a few instances the clinical situation will remain unsatisfactory. Two syndromes have been described. In one a normal or high CVP is associated with inadequate tissue perfusion and a low cardiac output. Some authors (for example, MacLean, 1966) believe the primary pathophysiology of these cases to be a cardiac insufficiency, and the logical therapy to be an attempt to improve cardiac function. Others, such as Vick et al. (1965), believe that this syndrome is due to continuing adrenergic hyperactivity, and that $\alpha$-adrenergic receptor blockade should be employed. Another clinical picture which may be seen is the development of pulmonary oedema at quite ordinary levels of CVP. There is a suggestion that this reaction is more likely when fluid replacement is given slowly (G. Walters, personal communication). Examples of both types of clinical situation have been reported by Brisman, Parks \& Benson (1967), who point out that in both situations the CVP taken alone is misleading.

For example, one patient with a CVP of $15 \mathrm{~cm}$ $\mathrm{H}_{2} \mathrm{O}$ had a low blood volume $(46 \mathrm{ml} / \mathrm{kg})$ and needed transfusing up to $18 \mathrm{~cm} \mathrm{H}_{2} \mathrm{O}$ before getting an adequate cardiac output, whereas another patient with a CVP of $11 \mathrm{~cm}$ and a tachycardia of 150 went into pulmonary oedema on further transfusion, was then found to have a blood volume of $104 \mathrm{ml} / \mathrm{kg}$ and improved on phlebotomy, although the CVP stayed the same.

In difficult diagnostic situations blood volume measurements can provide an additional guide to the relative contributions of intravascular volume and adrenergic activity to the resulting venous pressure. However, the magnitude of the difference between measured blood volume and predicted blood volume should not be accepted as a wholly reliable guide to transfusion. Blood volume is an additional measurement when the situation is unclear, and in only a small minority of cases does it provide the essential information for initiating the best therapy. To be of use, however, it must be both believed and interpreted. The former requires informed technique; the latter, clinical acumen.

\section{References}

Allen, T.H. \& Reeve, E.B. (1953) Distribution of 'extra plasma' in the blood of some tissues in the dog as measured with ${ }^{32} \mathrm{P}$ and T-1824. Amer. J. Physicl. 175, 218.
Birkeland, S. (1966) The question of the reliability of blood volume determinations in severe pathological states where the circulation is unstable, possibly with manifest clinical shock. Acta chir. scand. Suppl. 357, 136.

Brisman, R., Parks, L.C. \& Benson, D.W. (1967) Pitfalls in the clinical use of central venous pressure. Arch. Surg. (Chicago), 95, 902.

Brozovic, B., Korubin, V., Lewis, S.M. \& Szur, L. (1966) Simultaneous red cell and plasma volume determinations by a differential absorption method. J. Lab. clin. Med. 68, 142.

Chaplin, H., JR, Mollison, P.L. \& Vetter, H. (1953) The body/venous hematocrit ratio: its constancy over a wide hematocrit range. J. clin. Invest. 32, 1309.

Fisk, G.C. \& Bodlander, F.M.S. (1967) Sampling for serial blood volume estimations in children. Med. J. Aust. 1, 221.

Grable, E., Finck, A.J., Abrams, L. \& Williams, J.A. (1962) The effect of cyclopropane and halothane on the blood volume in man. Anesthesiology, 23, 828.

HeAth, M.L. \& Vickers, M.D. (1968) An examination of single-tracer semi-automated blood volume methodology. Anaesthesia, 23, 659.

Heath, M.L., Vickers, M.D. \& Dunlap, D. (1969) A simple accurate method for simultaneous measurement of plasma and red cell volumes. Brit. J. Anaesth. 41, No. 8.

Hope, A. \& Verel, D. (1955) Further observations on the distribution of red cells and plasma in disease-the low body haematocrit: venous haematocrit ratio. Clin. Sci. 14, 501.

Hoye, R.C., Ketcham, A.S. \& Berlin, N.I. (1966) Total red cell and plasma volume alterations occurring with extensive surgery in humans. Surg. Gynec. Obstet. 123, 27.

Karlson, K.E. \& SeNN, L.Y. (1963) Simultaneous determination of red cell mass and plasma volume with $\mathrm{Cr}^{51}$ and $\mathrm{I}^{131}$ using a pulse height analyzer. Ann. Surg. 158, 309.

MacLean, L.D. (1966) The clinical management of shock. Brit. J. Anaesth. 38, 255.

Nadler, S.B., Hidalgo, J.U. \& Bloch, T. (1962) Prediction of blood volume in normal human adults. Surgery, 51, 224.

Noble, R.P. \& Gregersen, M.I. (1946) Blood volume in clinical shock. I. Mixing time and disappearance rate of T-1824 in normal subjects and in patients in shock; determination of plasma volume in man from 10-minute sample. J. clin. Invest. 25, 158.

Pappenheimer, J.R. \& Kintner, W.B. (1956) Hematocrit ratio of blood within mammalian kidney and its significance for renal hemodynamics. Amer. J. Physiol. 185, 377.

Reeve, E.B., Gregersen, M.I., Allen, T.H. \& Sear, H. (1953) Distribution of cells and plasma in the normal and splenectomized dog and its influence on blood volume estimates with $\mathrm{P}^{32}$ and T-1824. Amer. J. Physiol. 175, 195.

Remington, J.W. \& BAKER, C.H. (1961) Evaluation of blood volume measurement techniques. Circulat. Res. 9, 60.

SMITH, L.L. \& MoORE, F.D. (1962) Refractory hypotension in man; is this irreversible shock? New Engl. J. Med. 267, 733.

Suzuki, F., Baker, R.J. \& Shoemaker, W.C. (1964) Red cell and plasma volume alterations after hemorrhage and trauma. Ann. Surg. 160, 263.

UNDERWOOD, P.S., BoYAN, C.P. \& Howland, W.S. (1966) Appraisal of RISA blood volume for clinical use. Anesth. Analg. Curr. Res. 45, 1.

Vick, J.A., Ciuchta, H.P., Merickel, J.H. \& Lindseth, E.O. (1965) Vasodilator therapy in acute hemorrhagic shock. Circulat. Res. 16, 58.

Weil, M.H., Shubin, H. \& Rosoff, L. (1965) Fluid repletion in circulatory shock. J. Amer. med. Ass. 192, 668. 